industrial sources of terrestrial contaminants. Moreover, the average annual temperature is $-60^{\circ} \mathrm{C}$ and the maximum temperature never exceeds $0^{\circ} \mathrm{C}$, so that materials precipitated are perfectly preserved and do not diffuse. There is also another important advantage. Although there are no known natural processes on Earth likely to give rise to ${ }^{5 \prime} \mathrm{Mn}$, this nuclide could be produced as a result of thermonuclear bomb tests in the atmosphere. There is apparently no published data which can either confirm or refute this possibility; and so in order to avoid the problem altogether it is necessary to investigate only snow which fell prior to 1952 . At the site in question the rate of snow accumulation has been extremely low, making it possible without too much difficulty to collect firn layers deposited well before nuclear testing began.

${ }^{5}{ }^{5} \mathrm{Mn}$ was detected in all three samples of snow analysed (corresponding to the period 1935-1950), the average activity being $0.82 \pm 0.17$ disintegrations per minute per $10^{3}$ tons of snow. This is apparently the first experimental evidence for the presence on Earth of the natural nuclide. But did it really originate from the supposed interplanetary dust? There is, in fact, another possibility-that the ${ }^{53} \mathrm{Mn}$ was produced not from the dust but from the material volatised or dispersed from meteorites during their flight through the atmosphere. To account for the observed ${ }^{5:} \mathrm{Mn}$ activity, however, the volatilisation of over $3 \times 10^{6}$ tons of chondritic material would have been required between 1935 and 1950 whereas, in spite of uncertainties in the estimates, it appears unlikely that the actual meteoritic influx exceeded $6 \times 10^{4}$ tons (or perhaps twice that, taking into account objects with preatmospheric masses of less than $10^{3} \mathrm{~g}$ ). In short, the meteoritic material available would have been insufficient by a factor of at least 25. Bibron and his colleagues thus conclude that the only possible source of the ${ }^{53} \mathrm{Mn}$ is indeed the interplanetary dust.

Accepting this conclusion they go on to estimate the total global influx of extraterrestrial dust. During the period 1935-1950 the rate of deposition of ${ }^{53} \mathrm{Mn}$ in Eastern Antarctica was (2.2 \pm $0.5) \times 10^{-5}$ disint. $\min ^{-1} \mathrm{~m}^{-2} \mathrm{yr}^{-1}$, although this is not a value which can be extrapolated directly to the whole Earth. It is probable that a significant proportion of the extraterrestrial material volatilises when it enters the atmosphere, becoming fixed on the stratospheric aerosols and thus ultimately being deposited in such a way that the concentration is maximum in temperate latitudes and minimum at the poles and the equator. The deposition in Antarctica should thus represent a lower limit of the average over the
Earth's surface. Assuming (in the absence of any more definite information) that the $\mathrm{Mn}$ distributes itself in a way similar to that of the ${ }^{10} \mathrm{Sr}$ injected into the stratosphere by thermonuclear explosions, Bibron et al. estimate the average global deposition of ${ }^{5} \mathrm{Mn}$ to be $(6.6 \pm 1.5) \times 10^{-5}$ disint. $\min ^{-1} \mathrm{~m}^{-2}$ $\mathrm{yr}^{-1}$. From this figure it is then possible to show that the interplanetary dust (assumed to have a chondritic composition) accumulates on the Earth at a rate of $1-6 \times 10^{5}$ tons a year.

In summary, then, Bibron and his colleagues have provided the first inputable (their word) evidence for the presence on Earth of ${ }^{53} \mathrm{Mn}$, a radionuclide thought to be formed only from interplanetary dust which builds up on the Earth at a rate of about $10^{5}$ tons a year. But this is only a beginning, for most of the questions about interplanetary dust remain unresolved. As Bibron et al. point out, a decisive step forward would be the simultaneous determination of ${ }^{{ }^{23}} \mathrm{Mn},{ }^{59} \mathrm{Nn}$ and ${ }^{26} \mathrm{Al}$, although there is still plenty of scope in tracing the variations of ${ }^{3} \mathrm{Mn}$ itself during the past hundred thousand years or so by analysing deep ice cores from polar ice sheets.

\section{Vegetational change in an aboriginal environment}

from Peter D. Moore

Plant Ecology Correspondent

EVER since Iversen (Danm. geol. Unders., 2R, 66, 1; 1941) described the influence of Neolithic cultures on the vegetation of Denmark, palaeocologists have been forced to accept the fact that the introduction of agricultural practices in north-west Europe (perhaps 3,500 radiocarbon years BP for the British Isles) profoundly altered the contemporary environment. More recent work has suggested that many of the vegetational changes which were once thought to be climatically determined must now be regarded as anthropogenic, for example the decline in lime (Tilia) in Britain (Turner, New Phytol., 61, $328 ; 1962)$ and the initiation of blanket peat formation (Moore, Nature, 241, $350 ; 1973)$. Some have even considered it possible that pre-agricultural Mesolithic cultures may have modified vegetation on a large scale by using fire to drive game or to favour selectively plant species which provide a source of food such as hazel, Corylus avellana (Rawitscher, Nature, 156, 302; 1945). This view has received some indirect support as the result of the recent work of Martin (Aust. J. Bot., 21, 283; 1973) on the environment of aborigines in the Nullabor region of South Australia.
Martin's interest has centred on the palynological analysis of three radiocarbon-dated cave deposit profiles and their interpretation in the light of modern pollen deposition in the area. Her modern pollen studies have provided a means of recognising past plant communities which, in this arid region, are fairly simple in composition.

The present vegetation of the Nullabor region consists of mallee scrub in the coastal region, which has a slightly higher precipitation $\left(23-25 \mathrm{~cm} \mathrm{yr}^{-1}\right)$ than the inland area $\left(16-18 \mathrm{~cm} \mathrm{yr}^{-1}\right)$. Tem. peratures in the two regions are virtually the same, but the number of rain days in the coastal region is roughly twice that experienced inland ( 80 rather than 30-50 d inland). In the arid interior there is tall, open scrub dominated by Acacia and Myoporum.

Palynologically the two vegetation types can be separated on the basis of the ratio of Myrtaceae (largely Eucalyptus and Melaleuca) pollen to that of Chenopodiaceae (many genera including Atriplex and Kochia). Surface pollen analyses in the arid scrub region consistently showed Myrtaceae : Chenopodiceae $(\mathrm{M}: \mathrm{C})$ ratios of less than 0.2 . $M: C$ ratios in samples from the less arid mallee scrub zone, on the other hand, were always in excess of 0.5 . This simple characteristic of the pollen fallout from the two vegetation types permitted Martin to recognise these communities in the fossil pollen assemblages of the cave deposits.

At one site (Eucla) the $\mathrm{M}: \mathrm{C}$ ratio increases from a low level at 20,000 BP to a maximum at the present day. Its rate of increase mirrors effectively the postglacial eustatic rise in sea level resulting from the gradual melting of the icecaps. The vegetational change in which arid scrub gives way to mallee can thus be explained by a rise in climatic wetness resulting from the increasing proximity of the coastline.

Two other sites tell a rather different story. They show an increasing abundance of mallee scrub (that is, a higher $\mathrm{M}: \mathrm{C}$ ratio) until about 4,000 BP when it apparently declined. The date of this decline coincides with an increasing abundance of aboriginal artefacts at these sites. The aborigines of recent times are known to have burned scrub extensively, both for ritualistic purposes and to encourage certain food plants, such as the wild gooseberry. Under the climatic stress of aridity it is quite feasible that repeated burning of the scrub could have reversed the trend in vegetational development caused by ameliorating climate and have produced an anthropogenic plagioclimax of arid scrub. This seems to be one of the best documented examples of the influence of a pre-domestication human culture on the course of vegetational development in a wide geographic region. 